\title{
CORRESPONDENCE
}

\section{Cardiovascular Risk Factors and Signs of Subclinical Atherosclerosis in the Heinz Nixdorf Recall Study}

by Prof. Dr. med. Raimund Erbel, Priv.-Doz. Dr. med. Stefan Möhlenkamp, Dr. rer. nat. Nils Lehmann et al. in volume 1-2/2008

\section{Risk Factor Sleep Apnea}

This is a very interesting study, but, as a sleep physician, I was surprised to find no mention of sleep apnea as an independent risk factor for the development of atherosclerosis.

The role of sleep apnea in promoting the development of atherosclerosis has been demonstrated in a large number of investigations and scientific studies. As a single example, a review article by Dr. Schulz of Giessen (Germany) that appeared in Deutsches Ärzteblatt in 2006 presented this relationship quite clearly.

In view of the (high) body-mass index of the participants in this study, I suspect that sleep apnea was a common problem among them.

DOI: 10.3238/arztebl.2008.0294a

Dr. med. Reinhard Zimmermann

Am Achdorfer Feld 17

84036 Landshut, Germany

Conflict of interest statement

The author states that he has no conflict of interest as defined by the guidelines of the International Committee of Medical Journal Editors.

\section{In Reply:}

We thank Dr. Zimmermann for pointing out that the sleep apnea syndrome is a cardiovascular risk factor.

The goal of the Heinz Nixdorf Recall Study is to determine the predictive value of coronary calcification (an indicator of subclinical atherosclerosis) for cardiovascular morbidity and mortality. Other indicators of subclinical atherosclerosis, such as intimal-medial thickness and plaque formation in the carotid artery and the $\mathrm{ABI}$ index for peripheral arterial occlusive disease, were looked at as well. In addition to the ECG and the stress ECG, anthropometric and psychosocial factors were analyzed.

Obstructive sleep apnea (OSA) elevates cardiovascular risk independently of other, often associated risk factors such as advanced age, obesity, and metabolic disorders (1-3). Large-scale epidemiological studies have shown that OSA is of particular importance as an independent risk factor for arterial hypertension $(2,3)$. Thus, according to published guidelines, a work-up of arterial hypertension should include screening for sleep apnea.

In the second phase of the Heinz Nixdorf Recall Study, which is currently in progress in cooperation with Prof. Teschler of the Ruhrlandklinik in Essen (Germany), due attention was paid to these facts and nocturnal respiratory monitoring was performed.
Because logistical difficulties prevented the performance of complete polysomnography - the goldstandard test for OSA - in all of the study subjects, a simple screening test of breathing during sleep was carried out (Apnea Link, Resmed, Sydney, Australia). Dr. Wessendorf and colleagues recently presented the initial findings: in the patient collective of the Heinz Nixdorf Recall Study, OSA was a frequent comorbidity, and its severity was correlated with the age, body-mass index, and waist-hip ratio of the patient. These results are in accordance with those in the published literature on the subject. An initial analysis has also shown an association with coronary calcification; we are currently studying the question whether this is true independently of other risk factors.

DOI: 10.3238/arztebl.2008.0294b

\section{REFERENCES}

1. Schulz R, Eisele HJ, Weissmann N, Seeger W: Obstruktive Schlafapnoe - ein wichtiger kardiovaskulärer Risikofaktor. Dtsch Arztebl 2006; 103: A 775-81.

2. Peppard PE, Young T, Palta M, Skatrud J: Prospective study of the association between sleep-disordered breathing and hypertension. N Engl J Med 2000; 342: 1378-84.

3. Shahar E, Whitney CW, Redline S, Lee ET, Newman AB, Javier NF et al.: Sleep-disordered breathing and cardiovascular disease: crosssectional result of the Sleep Heart Health Study. Am J Respir Crit Care Med 2001; 163: 19-25.

Prof. Dr. med. Raimund Erbel

for the Investigator Group of the Heinz Nixdorf Recall Study Klinik für Kardiologie

Universitätsklinikum Essen

Westdeutsches Herzzentrum Essen

Hufelandstr. 55

45122 Essen, Germany

erbel@uk-essen.de

\section{Conflict of interest statement}

Prof. Erbel has received support for the setting up of a scientific meeting from the Siemens company, Erlangen, Germany. 